\title{
Alzheimer-like neurotransmitter deficits in adult Down's syndrome brain tissue
}

\author{
H GODRIDGE,* G P REYNOLDS,* C CZUDEK, ${ }^{*}$ N A CALCUTT, $\dagger$ M BENTON \\ From the Departments of Pathology* and Physiology and Pharmacology, $\dagger$ University of Nottingham Medical \\ School, Queen's Medical Centre, Nottingham, and Risbridge Hospitalł, Kedington, Haverhill, Suffolk, UK
}

SUMMARY Brain tissue taken at necropsy from five cases of Down's syndrome and six controls was analysed for changes in neurotransmitter markers. Concentrations of noradrenaline (NA), dopamine (DA) and its major metabolite homovanillic acid (HVA), 5-hydroxytryptamine (5HT) and its metabolite 5-hydroxyindoleacetic acid (5HIAA) were determined by means of HPLC, whilst choline acetyltransferase (ChAT) was measured by a radiochemical technique. Significant reductions in NA, 5HT and ChAT were found in most cortical and subcortical regions of the Down's syndrome tissue investigated. The neuropathological lesions were assessed using a fluorescent stain for neuritic plaques and neurofibrillary tangles. These were present to varying extents in every Down's syndrome case except the youngest but were not found in control tissue of comparable age. The results indicate profound transmitter deficits and neuropathological abnormalities in adult patients with Down's syndrome, which closely resemble those of Alzheimer's disease.

It is well recognised that Down's syndrome patients who live past 35 years of age develop the neuropathological features usually associated with $\mathrm{Al}$ zheimer's disease. Light and electron microscopic investigation of brain tissue have confirmed the presence of apparently similar senile plaques and neurofibrillary tangles in patients as young as 17 years, which become more numerous with advancing age. ${ }^{1-5}$ The similarities between the two degenerative processes also extend to neurochemical parameters. Deficiencies of acetylcholinesterase (AChE) and choline acetyltransferase (ChAT) throughout the brain ${ }^{6}$ have recently been attributed in both disorders to loss of acetylcholine (ACh)-containing projections from the nucleus basalis of Meynert. ${ }^{7-9}$ Loss of cells from the locus coeruleus9 in adult Down's syndrome indicates damage to the ascending noradrenergic system resulting in reductions in hypothalamic $\mathbf{N A}^{10}$ which again parallels that of Alzheimer's disease, ${ }^{11} 12$ whilst evidence of altered DA function is less conclusive. ${ }^{1314}$ The central 5HT deficits reported in Alzheimer's disease ${ }^{1516}$ were, until recently, ${ }^{24}$

Address for reprint requests: Dr G P Reynolds, Department of Pathology, University of Nottingham Medical School, Queen's Medical Centre, Nottingham NG7 2UH, UK

Received 23 May 1986 and in revised form 13 August 1986. Accepted 15 August 1986. unconfirmed in Down's syndrome. ${ }^{17}$ However, neuronal loss from the cortical 5HT projection site, the dorsal tegmental nucleus of Raphe, previously found in Alzheimer's disease ${ }^{18}$ has also recently been identified in Down's syndrome. ${ }^{9}$

Preliminary work has revealed substantial deficits of NA, 5HT and 5HIAA in the hippocampus, temporal and frontal cortex in a group of five adult Down's syndrome patients. ${ }^{19}$ The work reported here has extended these findings to include measurement of DA, HVA and ChAT in several cortical and subcortical regions and attempts to assess the changes in terms of the histological abnormalities found within the tissue.

\section{Materials and methods}

Frozen post mortem brain tissue from five cases of Down's syndrome and six control patients without history of neurological or psychiatric disorder was obtained from the Cambridge Brain Tissue Bank and dissected and stored as

Table 1 Data of patients providing brain tissue

\begin{tabular}{llll}
\hline & Age $(y)$ & Sex & Post-mortem delay $(h)$ \\
\hline D.S. & $52.6 \pm 11.4$ & $3 \mathrm{M}, 2 \mathrm{~F}$ & $34 \cdot 2 \pm 37.9$ \\
Controls & $54.2 \pm 10 \cdot 4$ & $5 \mathrm{M}, 1 \mathrm{~F}$ & $35.7 \pm 21.6$ \\
\hline
\end{tabular}

Mean \pm s.d. 
Table 2 NA, 5HT, 5HIAA, DA, HVA and ChAT concentrations in adult post mortem brain tissue

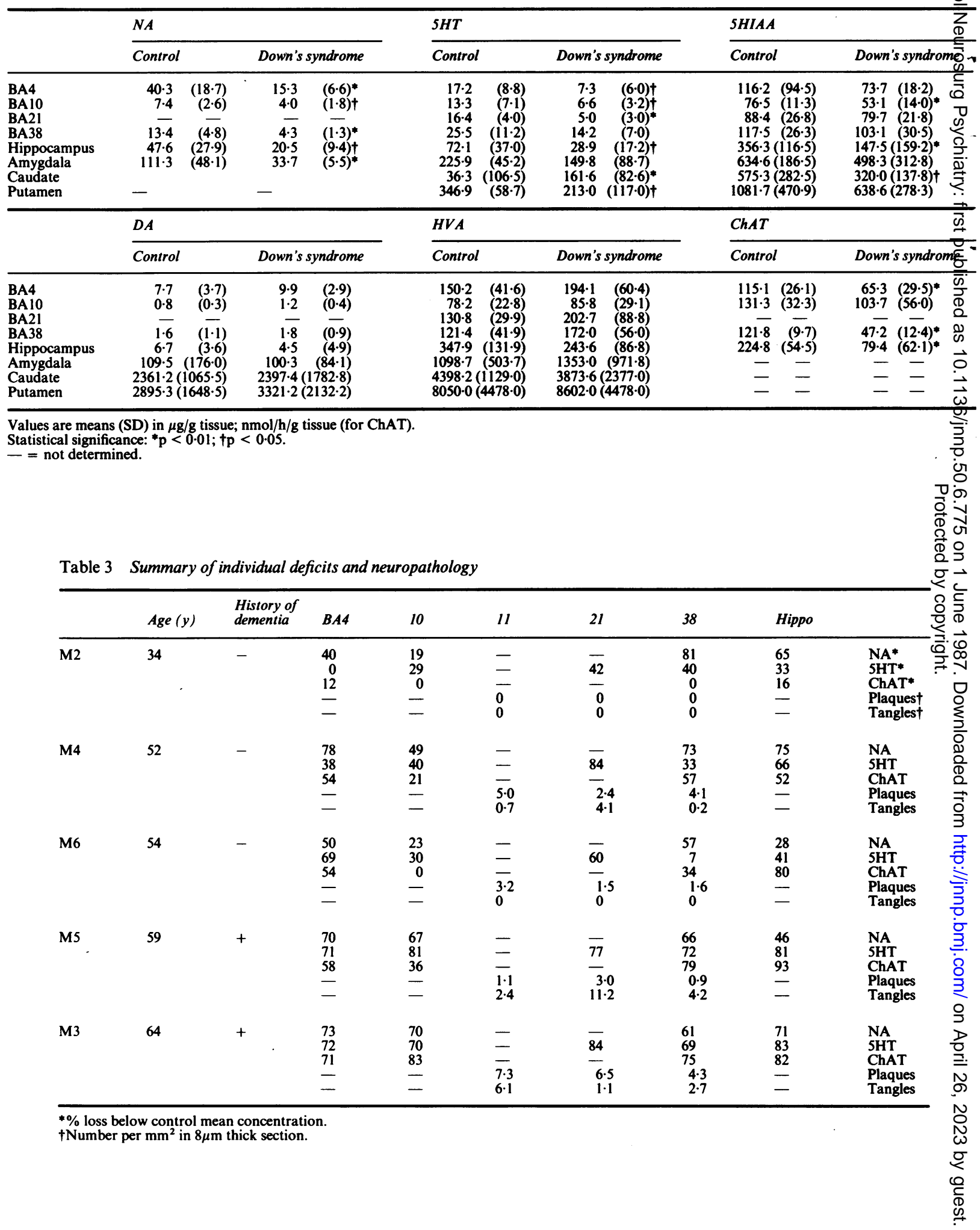


described elsewhere. ${ }^{20}$ The mean age and post mortem delay of the two groups were comparable (table 1).

NA, DA, 5HT, 5HIAA and HVA were determined simultaneously by HPLC with electrochemical detection from perchlorate homogenates of tissue using an alumina extraction procedure for NA and DA in non-striatal tissue samples. ${ }^{21}$ ChAT activity was determined by a modification of Fonnum's method ${ }^{22}$ reacting the samples with radiolabelled acetyl-CoA at $25^{\circ} \mathrm{C}$. Regions analysed by these techniques included frontal cortex (BA4 and 10), temporal cortex (BA21 and 38), hippocampus, amygdala, caudate and putamen.

Histological sections of formalin-fixed brain tissue were prepared by paraffin embedding, sectioning at $8 \mu$ and staining with Thioflavin $S\left(0 \cdot 1 \%\right.$ aqueous solution) for $7 \frac{1}{2}$ minutes. Using a fluorescence microscope, plaques and tangles were counted in fields of grey matter of frontal and temporal cortical sections.

The Mann-Whitney U test and Spearman Rank Correlation were employed for statistical analysis.

\section{Results}

The mean transmitter concentrations of control and Down's syndrome tissue are given in table 2. Those of NA were significantly lower in the Down's syndrome group in the five regions studied. 5HT was also reduced in all regions of Down's syndrome tissue achieving statistical significance in six of the eight with parallell, but less marked, losses of 5HIAA. DA and HVA concentrations were generally but insignificantly higher in the Down's syndrome tissue particularly within the cortex. One patient (M3) had a profound deficit of DA and HVA in the caudate (2\% and $15 \%$ of control values respectively) and putamen ( $24 \%$ and $28 \%$ ).

ChAT activity was only investigated in three cortical and one subcortical regions but was lower than control values in all regions of the Down's syndrome tissue, the difference being significant in three (table 2).

Plaques were found in profuse numbers throughout all Down's syndrome sections except those of case M2 and tangles were also found in all sections with the exception of those of M2 and M6. The densities, expressed as overall mean numbers per $\mathrm{mm}^{2}$ (table 3 ), show M3 to have the greatest number of plaques and M5 of tangles. No plaques or tangles were found in control tissue.

Tangle densities correlated with 5HT deficits in BA38 $\left(r_{s}=0.975, p<0.05\right)$ and ChAT and NA deficits in the frontal cortex $\left(r_{s}=0.975, p<0.05\right)$, whilst plaques showed no correlation with transmitter deficits but correlated with age in BA21 $\left(r_{s}=0.9, p<\right.$ 0.05 ). No other correlations between neuropathological and neurochemical parameters were statistically significant.

\section{Discussion}

The loss of cholinergic activity within the cortex and hippocampus of Down's syndrome cases over 35 years of age was confirmed with relative losses being comparable to previous work with both Down's syndrome and Alzheimer's disease brain tissue. ${ }^{1423}$ Severe cortical and limbic deficits of NA were found in the Down's syndrome group, these being consistent with the hypothalamic NA reductions ${ }^{1014}$ and damage to the locus coeruleus ${ }^{9}$ previously reported whilst being contrary to the conclusions of a report in which urinary transmitter concentrations were measured. ${ }^{13}$ The slightly increased DA and HVA concentrations were not consistent with previous reports of reduced urinary HVA ${ }^{13}$ and caudate DA. ${ }^{14}$

The results show severe losses of 5HT and its metabolite in all regions of Down's syndrome brain tissue and provides a further similarity with the changes observed in Alzheimer's disease. ${ }^{15} 16$ Since our initial report, ${ }^{19}$ this observation has been confirmed by Yates $e t a^{24}$ for Down's syndrome cases over 50 years old. They reported no loss in 5HT in a 27 year Down's syndrome case in the three regions (amygdala, cingulate, caudate) they studied. In our youngest case, M2 (34 years), 5HT did appear to be diminished particularly in the hippocampus and temporal cortex (table 3), although there were no clear losses in subcortical structures.

Selective loss of noradrenergic, cholinergic and serotoninergic transmitter systems have thus been ascribed to adult Down's syndrome cases, which appear to parallel those of the younger (less than 79 years) Alzheimer group in whom the biochemical deficits are more severe. ${ }^{25}$ The results exhibited correlations which also suggest that the transmitter deficits may be more specifically associated with tangle formation than with the development of plaques. Notable in this respect is the observation that the number of tangles correlates well with the index of dementia in Alzheimer's disease. ${ }^{26}$ Certainly the two eldest cases here, in whom a history of dementia had been noted, had the highest density of neocortical tangles.

The temporal cortex and hippocampus appear to be most severely affected biochemically both individually and as a group, which is again precedented in Alzheimer's disease. ${ }^{25}$ Individually the largest cholinergic and serotoninergic deficits occurred in the two eldest cases (aged 59 and 64), both of whom had a clinical history of dementia (table 3 ). In addition, the eldest case showed profound deficits of DA and HVA in striatal regions which would have been consistent with Parkinsonism. The youngest case, in whom plaques and tangles were absent, however, showed normal ChAT activities but substantial NA and 5HT deficits (table 3 ). These alterations are consistent with 
the report by Yates et al ${ }^{14}$ which suggested that noradrenergic damage may take place earlier in life. Whether this may also be true for serotoninergic systems is unclear; elucidating the relationship between neurotransmitter deficits and histopathology must await further studies with larger samples encompassing a broader age range.

This report has therefore shown that by middle age the brains of those with Down's syndrome have undergone profound, currently irreversible, neuronal degeneration involving three of the major neurotransmitter systems. The changes, which are very similar to those of Alzheimer's disease, may become more widespread within the brain with advancing age. The overlap of pathology between the two degenerative processes does not, however, necessarily indicate a common aetiology, since Down's syndrome encompasses a wide range of congenital defects not otherwise found in the population. Nevertheless, our understanding of Down's syndrome may shed light on the pathogenic mechanism of these changes in Alzheimer's disease.

We are most grateful to Professor G A Gresham and his staff at Addenbrooke's Hospital, Cambridge for assistance with the collection of brain tissue; to the staff of the Cambridge Brain Tissue Bank for provision of frozen tissue samples, and Dr CQ Mountjoy, Department of Psychiatry, Addenbrooke's Hospital for corresponding formalin-fixed tissue specimens. $\mathrm{CC}$ is supported by the Schizophrenia Research Fund.

\section{References}

1 Olson MJ, Shaw CM. Presenile dementia and Alzheimer's disease in mongolism. Brain 1969;92:147-56.

2 Malamud N. Neuropathology of organic brain syndromes associated with ageing. In: Gaitz GM, ed. Ageing and the Brain 1972:63-87.

3 Burger PG, Vogel FS. The development of the pathological changes of Alzheimer's disease and senile dementia in patients with Down's syndrome. Am J Pathol 1973;73:457-68.

4 Ellis WG, McCullough JH, Corley CL. Presenile dementia in Down's syndrome. Neurology 1974;24:101-6.

5 Wisniewkski KE, Wisniewski HM, Wen GY. Occurrence of neuropathological changes and dementia of Alzheimer's disease in Down's syndrome. Ann Neurol 1985;17:278-82.

6 Yates CM, Simpson J, Maloney AFJ, Gordon A, Reid AH. Alzheimer-like cholinergic deficiency in Down's syndrome. Lancet 1980;ii:979.

7 Price DL, Whitehouse PJ, Struble RG, Coyle JT, Clark AW, DeLong MR, Cork LC, Hedreen JC. Alzheimer's disease and Down's syndrome. Ann NY Acad Sci 1982;396:145-64.

8 Casanova MF, Walker LC, Whitehouse PJ, Price DL. Abnormalities of the nucleus basalis in Down's syn- . drome. Ann Neurol 1985;18:310-4.
9 Mann DMA, Yates PO, Marcyniuk B, Rawndra CR. Pathological evidence for neurotransmitter deficits in Down's syndrome of middle age. J Ment Defic Res 1985;29:125-35.

10 Yates CM, Ritchie IM, Simpson J, Maloney AFJ, Gordon A. Noradrenaline in Alzheimer-type dementia and Down's syndrome. Lancet 1981;ii:39-40.

11 Adolfsson R, Gottfries CG, Rosa BE, Winblad B. Post mortem distribution of dopamine and homovanillic acid in human brain, variations related to age, and a review of the literature. $J$ Neurol Transm 1979;45:81-105.

12 Bondareff W, Mountjoy CQ, Roth M. Selective loss of neurons of origin of noradrenergic projection to cerebral cortex (nucleus locus coeruleus) in senile dementia. Lancet 1979;i:783-4.

13 Mann DMA, Lincoln J, Yates PO, Brennan CM. Monoamine metabolism in Down's syndrome. Lancet 1980;ii:1366-7.

14 Yates CM, Simpson J, Gordon A, et al. Catecholamines and cholinergic enzymes in presenile and senile Alzheimer-type dementia and Down's syndrome. Brain Res 1983;280:119-26.

15 Bowen DM, Allen SJ, Benton JS, et al. Biochemical assessment of serotonergic and cholinergic dysfunction and cerebral atrophy in Alzheimer's disease. $J$ Neurochem 1983;41:266-72.

16 Arai H, Koskaki K, Iizuka R. Changes of biogenic amines and their metabolites in post mortem brains from patients with Alzheimer-type dementia. $J$ Neurochem 1984;43:288-393.

17 Nyberg P, Carlsson A, Winblad B. Brain monoamines in cases with Down's syndrome with and without dementia. J Neural Transm 1982;55:289-300.

18 Mann DMA, Yates PO. Serotonin nerve cells in Alzheimer's disease. J Neurol Neurosurg Psychiatry 1983;46:96-8.

19 Reynolds GP, Godridge H. Alzheimer-like monoamine deficits in adults with Down's syndrome. Lancet 1985;ii:1368-9.

20 Spokes EGS. An analysis of factors influencing measurements of dopamine, noradrenaline, glutamate decarboxylase and choline acetylase in human post mortem tissue. Brain 1979;102:338-46.

21 Reynolds GP. Increased concentrations and lateral asymmetry of amygdala dopamine in schizophrenia. Nature 1983;305:527-9.

22 Tomlinson DR, Moriarty RJ, Mayer JH. Prevention and reversal of defective axonal transport and motor nerve conduction velocity in rats with experimental diabetes by treatment with the aldose reductase inhibitor Sorbinil. Diabetes 1984;33:470-6.

23 Perry EK, Perry RH, Blessed G, Tomlinson BE. Necropsy evidence of central cholinergic deficits in senile dementia. Lancet 1977;i:189.

24 Yates C, Simpson J, Gordon A. Regional brain 5-hydroxytryptamine levels are reduced in senile Down's syndrome as in Alzheimer's disease. Neurosci Lett 1986;65:189-92.

25 Rossor MN, Iversen LL, Reynolds GP, Mountjoy CQ, Roth M. Neurochemical characteristics of early and late onset types of Alzheimer's disease. $\mathrm{Br} \mathrm{Med} J$ 1984;288:961-4.

26 Wilcock G, Esiri MM. Plaques, tangles and dementia. A quantitative study. J Neurol Sci 1982;56:343-56. 